\title{
Patient Physiological Condition
}

National Cancer Institute

\section{Source}

National Cancer Institute. Patient Physiological Condition. NCI Thesaurus. Code C69192.

A description of the physiological status of a patient. 